\title{
|||||||||||||||||||||||||||||||||||||||||||||||||||||||||||||||||||.
}

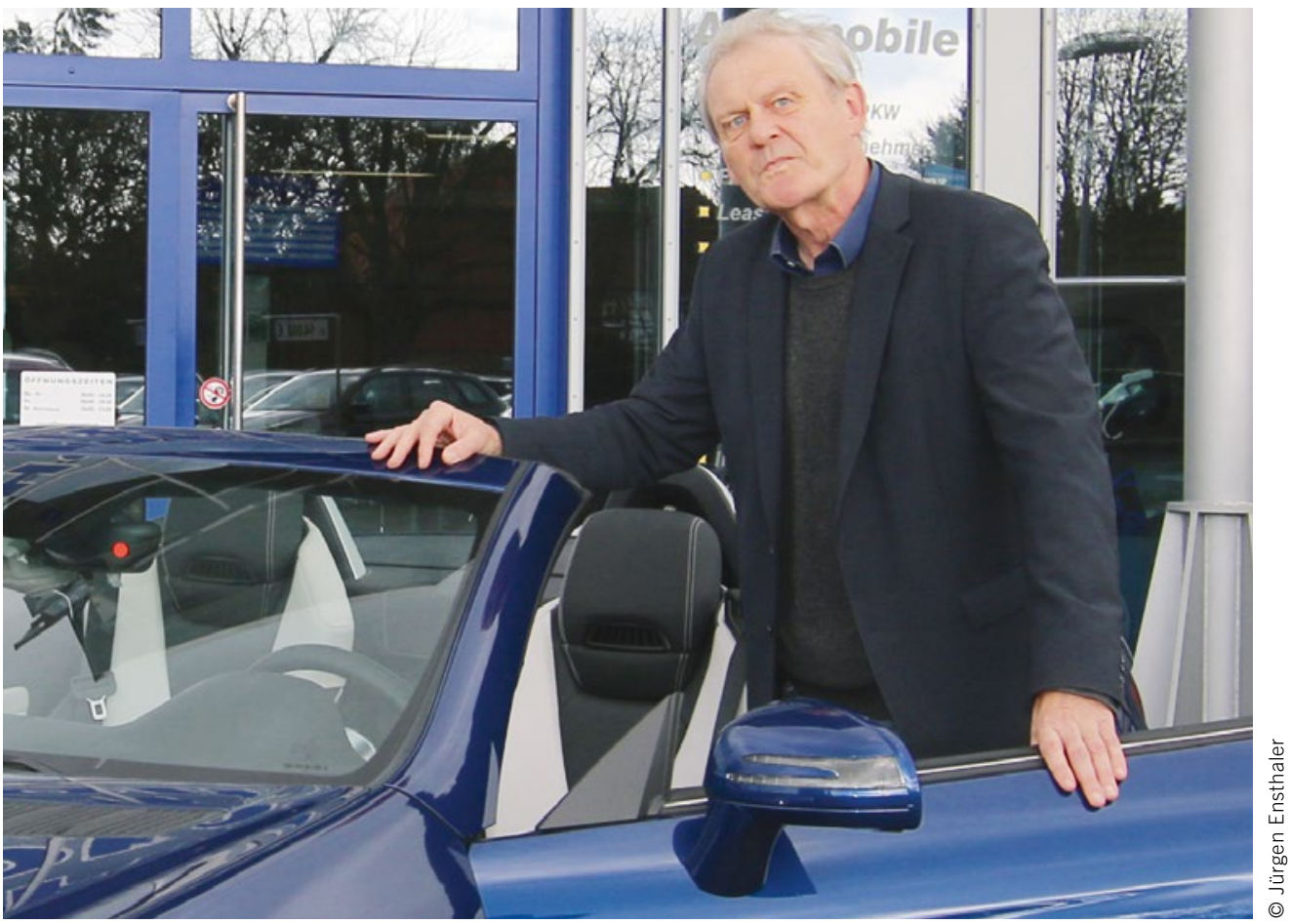

Prof. Dr. Dr. Jürgen Ensthaler Inhaber des Lehrstuhls für Wirtschafts-, Unternehmensund Technikrecht an der TU Berlin

\section{Rechtliches zum vernetzten Fahren}

Probleme gibt es bereits beim Zugang zur Technik, die für das automatisierte und vernetzte Fahren nötig ist. Von verschiedenen Telekommunikationsunternehmen, insbesondere US-amerikanischen, werden Patente für Technologien zur Vernetzung gehalten, die im Rahmen des vollautomatisierten Fahrens essenziell sind und von Autoherstellern implementiert werden müssen. Die Begehrlichkeiten hinsichtlich der Lizenzgebühren sind groß. Der europäische Gerichtshof hat in einer Grundsatzentscheidung zumindest Klarheit hinsichtlich der Nutzungsmöglichkeiten vor einer Einigung über die Lizenzgebühren geschaffen; trotz Streit über die Höhe der Lizenzgebühren darf die Technologie genutzt werden. Über die Berechnung der Gebühren herrscht nach wie vor Uneinigkeit.

Die zulassungsrechtliche Besonderheit der neuen Technologie liegt darin, dass künftig die Technik vielfach nicht mehr auf den Fahrer bezogen ist, sondern die Systeme autonom funktionieren. Die Technik muss demnach den erfahrenen Fahrer vollumfänglich ersetzen (können). Eine Technik, die schlechter als der gute Fahrer steuert, ist schon aus ethischen Gründen ausgeschlossen. Damit kommt man zum Haftungsrecht. Der Zusammenhang von Halter-, Produzenten- und Infrastrukturhaftung muss neu justiert werden. Die Automobilunternehmen entwickeln im Rahmen der neuen Technologien auch Infrastruktureinrichtungen, für die eigentlich der Staat verantwortlich ist, und es ist sehr fraglich, ob der Konsument für alle
Prozesse im Rahmen der Halterhaftung verantwortlich gemacht werden kann, deren Wirkweise er nicht mehr beeinflussen kann. Problematisch wäre die weiterhin allein auf den Halter bezogene Haftung, wenn man bedenkt, dass der Halter im Fall des Versagens technischer Einrichtungen Regressansprüche gegen die Hersteller hätte. Regressansprüche kann aber nur der durchsetzen, der weiß, wer welchen Fehler verursacht hat bei vernetzten Systemen ein sehr schwieriges Unterfangen. Letztlich wird hier vieles davon abhängen, in welchem Umfang die Versicherungen das alte Modell der Halterhaftung mittragen wollen. Wenn die neue Technik hält, was man erhofft, wird es weniger Unfälle geben. Und dieses Argument mag genügen, auch Schäden auszugleichen, die bislang nicht zum Leistungsbereich der Versicherer gerechnet wurden.

Völlig ungeklärt ist bis heute, wem die im Zusammenhang mit dem Fahren generierten übermittelten Daten gehören. Gehören sie dem Fahrer, der sie generiert, oder dem Hersteller, der die Generierung ermöglicht? Problematisch sind weiterhin Datensicherheitskonzepte. Die Gewährleistung der Sicherheit vor Hackerangriffen ist ein zentrales Problem, dessen Lösungserfolge bislang sehr kontrovers diskutiert werden. Aber auch für die rechtlichen Rahmenbedingungen gilt, dass die Probleme lösbar sind. Gefordert sind Juristen, die die neuen Sachverhalte verstehen, um dann die Möglichkeiten der Rechtsinstitute auszunutzen. 